\section{Insect Management in Floriculture: How Important Is Sanitation in Avoiding Insect Problems?}

\author{
Brian K. Hogendorp and Raymond A. Cloyd
}

\begin{abstract}
AdDitionAl INDEX WORDs. cultural control, refuse containers, debris, disposal, greenhouse

SuMmARY. Sanitation, which includes removing plant and growing medium debris, is an important component of any greenhouse or nursery pest management program. However, there is minimal quantitative information on how sanitation practices can reduce pest problems. In this study, conducted from May through Nov. 2005, we evaluated plant and growing medium debris as a source of insect pests from four greenhouses located in central Illinois. Two 32-gal refuse containers were placed in each greenhouse with a $3 \times 5$-inch yellow sticky card attached to the underside of each refuse container lid. Each week, yellow sticky cards and plastic refuse bags were collected from the containers and insects captured on the yellow sticky cards were identified. Insects captured on the yellow sticky cards were consistent across the four greenhouses with western flower thrips (Frankliniella occidentalis), fungus gnats (Bradysia spp.), and whiteflies (Bemisia spp.) the primary insects present each week. Insect numbers, in order of prevalence on the yellow sticky cards, varied across the four locations, which may be related to the type of plant debris discarded. For example, extremely high numbers of adult whiteflies (range $=702$ to 1930) were captured on yellow sticky cards in one greenhouse each month from August through November. This was due to the presence of yellow sage (Lantana camera), bee balm (Monarda didyma), garden verbena (Verbena $\times$ bybrida), common zinnia (Zinnia elegans), sage (Salvia spp.) and fuchsia (Fuschia spp.) debris that was heavily-infested with the egg, nymph, pupa, and adult stages of whiteflies. High western flower thrips adult numbers in the greenhouses were generally associated with plant types such as marguerite daisy (Dendranthema frutescens) and pot marigold (Calendula officinalis) disposed while in bloom with opened yellow flowers, which contained adult western flower thrips. Based on the results of this study, it is important that greenhouse producers timely remove plant and growing medium debris from greenhouses or place debris into refuse containers with tight-sealing lids to prevent insect pests from escaping.
\end{abstract}

$\mathrm{C}$ ultural control is often recommended as a strategy to avoid insect, mite, and disease problems in greenhouses (Ferguson and Shipp, 1994). Cultural control involves properly implementing irrigation and fertility practices, and sanitation, which includes timely weed, and plant and growing medium debris removal (Cloyd, 2003). Sanitation is an important component of pest management programs in greenhouses, and may reduce problems with plant pathogens. The removal of plant de-

Department of Natural Resources and Environmental Sciences, University of Illinois, 1101 West Peabody Drive, Urbana, IL 61801

Acknowledgments. We thank Nathan Campbell, owner of Danville Gardens (Danville, Ill.), for his cooperation in allowing us to use his greenhouse facilities for this study. We also wish to acknowledge Jack Juvik, Department of Natural Resources and Environmental Sciences, University of Illinois, Champaign-Urbana, for his valuable contribution in critically reviewing the manuscript. bris can eliminate or reduce conidia and vegetative hyphae, which are a source of inoculum for many plant pathogens (Agrios, 1988; Hausbeck and Moorman, 1996; Jarvis, 1992). Disposal of infected plant material into covered containers may reduce the concentration of airborne conidia. For example, plant debris placed into uncovered containers may allow fungi such as Botrytis cinerea to sporulate, releasing and dispersing spores that can infect many crops (Hausbeck and Moorman, 1996). It is interesting to note that research is more extensive on the impact of sanitation as a means of reducing problems with plant diseases than for phytophagous insects
(Jarvis, 1994). However, sanitation is also important in either preventing or reducing insect infestations by removing breeding and hibernating sites (National Academy of Sciences, 1969). It is generally recommended to avoid keeping refuse containers in greenhouses; although, due to convenience, refuse containers are typically positioned in greenhouses. If this is the case, then it is important to cover refuse containers to prevent spores from developing on plant debris and re-infecting the main crop via air currents (Hausbeck, 2005). In addition, insect pests completing development on plant or in growing medium debris may also be able to migrate onto the main crop. This is likely the case for the adult stages of insects such as western flower thrips, fungus gnats, shoreflies (Scatella spp.), leafminers (Liriomyza spp.), and whiteflies.

There is minimal, if any, quantitative data to substantiate the impact of sanitation in greenhouse insect pest control. This study was designed to evaluate the abundance and types of insect pests emerging from plant and growing medium debris disposed into refuse containers located within greenhouses.

\section{Materials and methods}

This study was conducted in two greenhouses located at Danville Gardens (Danville, Ill.), and two greenhouses located at the University of Illinois (Urbana); in the plant sciences facility and the Turner Hall facility. These greenhouses were selected based on the diversity of plant material grown and level of production. For example, Danville Gardens is a commercial wholesale and retail operation whereas the greenhouses located at the University of Illinois are primarily used for research, teaching, and collection activities. All greenhouse refuse collected was assumed to be general greenhouse debris. Each refuse container (described below) was placed near walkways and pathways, in order to increase accessibility. The employees responsible for each greenhouse were instructed to treat the selected refuse containers as regular containers to

\begin{tabular}{llll}
\hline $\begin{array}{l}\text { Units } \\
\begin{array}{l}\text { To convert U.S. to SI, } \\
\text { multiply by }\end{array}\end{array}$ & U.S. unit & SI unit & $\begin{array}{l}\text { To convert SI to U.S., } \\
\text { multiply by }\end{array}$ \\
\hline 3.7854 & gal & L & 0.2642 \\
2.54 & inch(es) & cm & 0.3937
\end{tabular}


avoid disrupting any routine disposal habits. Greenhouse debris was collected weekly for 28 weeks from May through Nov. 2005.

We used eight 32-gal Roughneck Rubbermaid refuse containers with tight-sealing lids (Rubbermaid Home Products, Wooster, Ohio) for the study. A 39-gal, black plastic refuse bag (Do It, Fort Wayne, Ind.) was placed into each container. Two containers were placed in each of the four greenhouses. A 3.0-cm-wide medium foldback binder clip (OMX, Inc., Shaker Heights, Ohio) was secured to the underside of the refuse container lid. The binder clip was fastened in place using a $1 / 4$-inch washer and a corresponding $1 / 4$-inch machine screw nut, which secured the binder clip to the underside of the refuse container lid. The placement of this assembly combination was designed so that a 3 $\times 5$-inch yellow sticky card (Whitmire Micro-Gen Research Laboratories, St. Louis) could be secured to the center of the lid when placed inside the binder clip holder (Fig. 1).

A label was attached to the side of the refuse container; centered inbetween the handles. The label stated only plant material and growing medium debris were to be placed in the refuse container. Additionally, the refuse containers were labeled so that they would not be accidentally emptied. The week and a refuse container code were handwritten on the back of each yellow sticky card so the refuse container and yellow sticky card could be correctly identified.

Each week, over the 28-week period, the yellow sticky cards and black plastic refuse bags were collected from the refuse containers, and replaced with new yellow sticky cards and refuse bags. The yellow sticky cards were collected as follows. First, the lid was detached from the refuse container and then the yellow sticky card was removed from the binder clip and covered with clear plastic food wrap (Presto Products Co., Appleton, Wis.). Sticky cards were replaced weekly and stored for later evaluation. Insects captured on the yellow sticky cards were identified, at least to type, and the total number of each type was determined using a dissecting microscope (SMZ1000 zoom stereomicroscope; Nikon Inc., Torrance, Calif.).

After the yellow sticky card was replaced, the black plastic refuse bag was removed, sealed, and returned to the plant sciences facility. Each refuse bag was labeled, based on the refuse container code and the designated week, to ensure proper coordination when coupled with the appropriate yellow sticky card. The material in each refuse bag was partitioned, quantified (based on percent), and plant material debris identified. All plant material refuse was separated from the growing medium. A percentage estimate, based on an objective visual assessment, was used to quantify the general ratio of growing medium to plant material debris. Once this procedure was completed, the plant material refuse was separated, based on plant genera and species. The amount (based on percent) of each plant type present was quantified, again by visual assessment, in relation to the overall amount of plant material debris present in the refuse container. All percentage values were recorded. Data were compiled based on refuse container, week, and greenhouse. The type and number of insects present on the yellow sticky cards were coupled with the corresponding greenhouse debris, both growing medium and plant material, present in each refuse container.

\section{Results and discussion}

This study is the first to quantitatively demonstrate that plant material

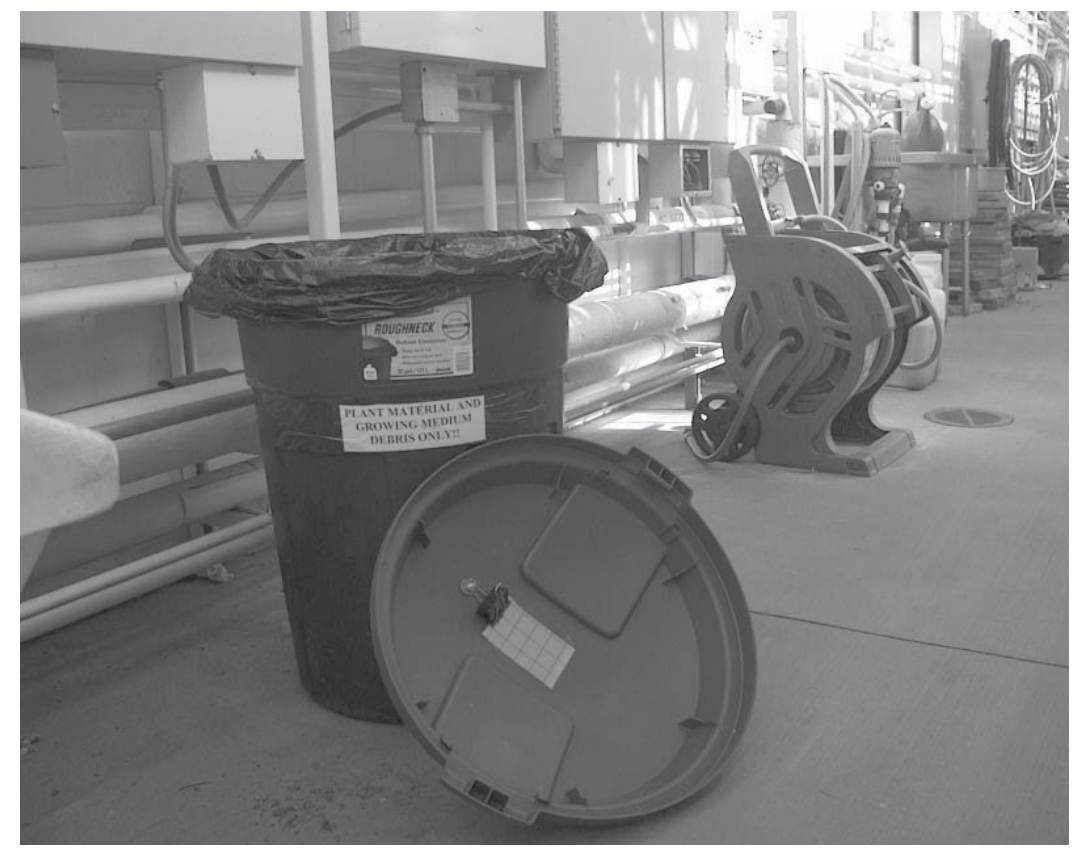

Fig. 1. A 32-gal (121.1 L) refuse container and lid with the assembly combination designed to hold a $3 \times 5$-inch $(7.6 \times 12.7 \mathrm{~cm})$ yellow sticky card to the underside of the lid. and growing medium debris placed into refuse containers may serve as a source for insect pests. The number of insect pests on the yellow sticky cards varied among the four locations (Table 1), which is likely associated with the plant debris discarded in the refuse containers. Insects recovered on the yellow sticky cards were consistent among the four greenhouses with western flower thrips, whiteflies, and fungus gnats the insects typically recovered each week. The primary horticultural crops retrieved from the refuse containers, based on prevalence, in all four greenhouses throughout the study are presented in Table 2 . The percentage of growing medium in the refuse containers varied widely from $0 \%$ to $100 \%$, depending on the greenhouse and month. As such, we were not able to demonstrate any relationship between the volume of growing medium recovered from refuse containers and adult fungus gnat abundance. All the numbers obtained for each insect type in the study represented a nearly accurate assessment of what was present in the refuse containers since the tight-sealing lids, in general, prevented insects from escaping.

Western flower thrips adult counts on the yellow sticky cards for the months of June $(\mathrm{n}=117)$ and July $(\mathrm{n}=9 \mathrm{l})$ in the second greenhouse at Danville Gardens (Table 1) 
Table 1. Total number of adult western flower thrips (WFT), fungus gnats (FG), and whiteflies (WF) captured per month from May through Nov. 2005 on $3 \times 5$-inch $(7.6 \times 12.7 \mathrm{~cm})$ yellow sticky cards secured to the lid underside of 32 -gal $(121.1 \mathrm{~L})$ refuse containers positioned in the four greenhouses; Danville Gardens No. 1 and No. 2 (Danville, Ill.), Plant Sciences Facility (Urbana, Ill.), and Turner Hall (Urbana, Ill.).

\begin{tabular}{|c|c|c|c|c|c|c|c|c|c|c|c|c|}
\hline \multirow[b]{3}{*}{ Month } & \multicolumn{12}{|c|}{ Insects captured (no./month) for each greenhouse location } \\
\hline & \multicolumn{3}{|c|}{ Danville Gardens No. 1} & \multicolumn{3}{|c|}{ Danville Gardens No. 2} & \multicolumn{3}{|c|}{ Plant Sciences Facility } & \multicolumn{3}{|c|}{ Turner Hall } \\
\hline & WFT & FG & WF & WFT & FG & $\overline{W F}$ & WFT & FG & WF & WFT & FG & WF \\
\hline June & 104 & 5 & 0 & 117 & 16 & 0 & 8 & 0 & 3 & 114 & 33 & 107 \\
\hline July & 32 & 2 & 0 & 91 & 22 & 0 & 3 & 2 & 5 & 28 & 23 & 62 \\
\hline Aug. & 4 & 33 & 20 & 3 & 42 & 2 & 7 & 7 & 21 & 9 & 32 & 1244 \\
\hline Nov. & 0 & 5 & 0 & 0 & 1 & 2 & 0 & 5 & 1 & 1 & 2 & 1930 \\
\hline
\end{tabular}

was likely due to the plant material recovered, including chrysanthemum (Dendranthema grandiflora) and impatiens (Impatiens wallerana), which are both susceptible to western flower thrips (Daughtrey et al., 1995). The percentage of western flower thrips adults, out of the total number of insects captured on the yellow sticky cards, ranged from $73 \%$ to $97 \%$, while the percentage of chrysanthemum and impatiens debris present in the refuse containers ranged from $15 \%$ to $65 \%$. The whitefly adult counts on the yellow sticky cards $(\mathrm{n}=176)$ for October in the second greenhouse at Danville Gardens was probably associated with the presence of plant material such as poinsettia (Euphorbia pulcherrima), which is highly susceptible to whiteflies (Dreistadt, 2001). In fact, when the percentage of poinsettia debris present in the refuse containers was $100 \%$, the percent adult whiteflies captured on the yellow sticky cards was $>98 \%$.

The reason for the low numbers of insects, including western flower thrips and whiteflies, recovered on yellow sticky cards in the refuse containers located in the plant sciences facility greenhouse (Table 1), compared to the other greenhouses, is that this greenhouse contains primarily foliage plants for collections such as dumb cane (Dieffenbachia spp.), tailflower (Anthurium spp.), creeping fig (Ficus pumila), english ivy (Hedera helix), and arrowhead vine (Syngonium podophyllum), which may be less susceptible to these specific insect pests. However, most of these foliage plants are more susceptible to citrus mealybug (Planococcus citri), longtailed mealybug (Pseudococcus longispinus), and brown soft scale (Coccus hesperidium), which are less likely to be captured on yel-

Table 2. Plants retrieved consistently, based on prevalence, from the 32 -gal $(121.1 \mathrm{~L})$ refuse containers in each of four greenhouses from May through Nov. 2005.

\begin{tabular}{ll}
\hline Greenhouse location & \multicolumn{1}{c}{ Plants } \\
\hline Danville Gardens No. I (Danville, Ill.) & Geranium (Pelargonium spp.) \\
& Common garden petunia (Petunia ×hybrida) \\
& Chrysanthemum (Dendranthema grandiflora) \\
& Wild cabbage (Brassica oleracea) \\
Danville Gardens No. 2 (Danville, Ill.) & Geranium \\
& Poinsettia (Euphorbia pulcherrima) \\
& Chrysanthemum \\
& Garden verbena (Verbena $\times$ bybrida) \\
Plant Sciences Facility (Urbana, Ill.) & Coleus (Solenostemon scutellarioides) \\
& English ivy (Hedera helix) \\
& Creeping fig (Ficus pumila) \\
& Arrowhead vine (Syngonium podophyllum) \\
& Coleus \\
Turner Hall (Urbana, Ill.) & Yellow sage (Lantana camera) \\
& Sweet-potato vine (Ipomoea batatas) \\
& Bee-balm (Monarda didyma) \\
\hline
\end{tabular}

low sticky cards since most of the life stages, with the exception of the mature males, cannot fly (Malais and Ravensberg, 2002).

The high adult whitefly counts on the yellow sticky cards per month from August through November associated with the Turner Hall facility greenhouse (Table 1) was related to the plant types disposed of during that time period. We found yellow sage, bee balm, garden verbena, common zinnia, sage, and fuchsia debris heavily infested with the egg, nymph, pupa, and adult stages of whitefly. Although the percentage of each plant type, from the total amount of plant material discarded in the refuse containers, was low (yellow sage $=15 \%$; bee balm $=$ $15 \%$; garden verbena $=20 \%$; common zinnia $\leq 30 \%$; sage $\leq 30 \%$; and fuchsia $=$ $10 \%$ ) the percentage of whitefly adults, out of the total number of insects cap- tured on the yellow sticky cards, was $\geq 96 \%$. This indicates that just a small quantity of susceptible plant material, when disposed of, may harbor large numbers of insect pests. All the plant types mentioned above are highly susceptible to whiteflies (Dreistadt, 1994, 2001).

During the l-week time periods in-between collection, it is possible that western flower thrips, fungus gnats, and whiteflies were able to develop from pupae to adults (Tsai and Wang, 1996), which were then captured on the yellow sticky cards before the debris desiccated. In the absence of tight-sealing lids covering refuse containers, these whitefly adults may have migrated onto crops present in the greenhouse.

The high numbers of western flower thrips adults captured on the yellow sticky cards $(\mathrm{n}=222)$ in the 
Turner Hall greenhouse during May (Table 1) was likely due to the plant debris disposed of, which included marguerite daisy and pot marigold. The marguerite daisy debris comprised $50 \%$ whereas the pot marigold was only $5 \%$ of the total plant material present in the refuse containers. Despite this, the percentage of western flower thrips adults was $\geq 80 \%$ of the total number of insects captured on the yellow sticky cards. However, these plant types were disposed of while in bloom and had opened yellow flowers, which contained adult western flower thrips. Western flower thrips adults are attracted to yellow-colored flowers (Blumthal et al., 2005; Guam and Pringle, 1994), and were likely captured on the yellow sticky cards as the flowers desiccated. Similar to whiteflies discussed above, these adult western flower thrips may have migrated from refuse containers without tight-sealing lids onto any plant material present in the greenhouse. Furthermore, it is apparent that a small quantity of susceptible plant material debris, when disposed of, is able to sustain a high population of western flower thrips.

Adult whitefly adult counts on the yellow sticky cards $(\mathrm{n}=107)$ for June in the Turner Hall greenhouse (Table 1) was likely associated with the plant material debris discarded into the refuse containers. For example, we recovered rose-of-china (Hibiscus rosa-sinensis) plants, which constituted $80 \%$ of the plant material discarded in the refuse containers, infested with whitefly nymphs, pupae, and adults. The percentage of adult whiteflies was $80 \%$ of the total number of insects captured on the yellow sticky cards. Rose-of-china is very susceptible to many species of whiteflies (Dreistadt, 2001).

If greenhouse producers fail to place tight-sealing lids onto refuse containers or do not remove plant and growing medium debris from the greenhouse before it desiccates or decomposes then any insect pests may potentially leave the debris and migrate onto the main crop. For example, as plant material debris desiccates, western flower thrips adults are likely to abandon the dry plant debris and locate the main crop; possibly vectoring viruses such as impatiens necrotic spot virus.

Any insect pests in refuse containers typically escape sprays of insecticides and then can migrate onto the main crop after spray residues dry. If these insect pests are captured on yellow sticky cards, then greenhouse producers may perceive inadequate control from the insecticide application. In addition, insects migrating out of refuse containers onto the main crop may overwhelm and thus reduce the effectiveness of natural enemies.

The adult stage of certain insect pests may attach themselves to greenhouse employees as they walk by open refuse containers wearing yellow-colored clothing, which is attractive to insect pests such as western flower thrips and whiteflies (MacDowell, 1972; Mound, 1962; Terry, 1997). This may inadvertently distribute these insect pests between or among greenhouses, thus initiating new infestations in areas previously pest-free.

Cultural control practices such as sanitation are typically the easiest and least expensive to implement because they are performed during normal operating procedures. In fact, proper disposal of waste and plant debris is one of the most effective ways of controlling many insects (National Academy of Sciences, 1969). This also avoids the problems associated with insecticides, such as resistance and environmental contamination (National Academy of Sciences, 1969). Greenhouse producers that implement sanitation practices on a routine basis may not have to spray as often for insect pests, which may lead to a reduction in insecticide usage.

This study has demonstrated that it is important to remove plant and growing medium debris from greenhouses or at least place into refuse containers with tight-sealing lids. In addition, greenhouse producers that leave refuse containers in greenhouses may want to consider coating the inside of the lid with a sticky substance or adhesive to trap insects. Sanitation is an important component of any pest management program; however, this practice must be used in conjunction with alternative management strategies, including the use of insecticides or natural enemies in order to minimize problems with plant-feeding insects in greenhouses.

\section{Literature cited}

Agrios, G.N. 1988. Plant pathology, 3rd ed. Academic Press, San Diego.

Blumthal, M.R., R.A. Cloyd, L.A. Spomer, and D.F. Warnock. 2005. Flower color preferences of western flower thrips. HortTechnology 15(4):846-853.

Cloyd, R.A. 2003. Managing insects and mites, p. 113-125. In: D. Hamrick (ed.). Ball redbook crop production, Vol. 2, 17th ed. Ball Publ., Batavia, Ill.

Daughtrey, M.L., R.L. Wick, and J.L. Peterson. 1995. Compendium of flowering potted plant diseases. APS Press, St. Paul, Minn.

Dreistadt, S.H. 1994. Pests of landscape trees and shrubs. Univ. of California, Div. Agr. and Natural Resources, Publ. 3359.

Dreistadt, S.H. 2001. Integrated pest management for floriculture and nurseries. Univ. of California, Statewide Integrated Pest Mgt. Project, Div. Agr. and Natural Resources, Publ. 3402.

Ferguson, G.M. and J.L. Shipp. 1994. Sanitation recommendations for management of insect and mite pests of greenhouse vegetables. Ontario Ministry of Agr., Food and Rural Affairs Fact Sheet 290/621.

Guam, W.G. and J.H. Pringle. 1994. Resistance of some rose cultivars to the western flower thrips, Frankliniella occidentalis (Thysanoptera: Thripidae). Bul. Entomol. Res. 84:487-492.

Hausbeck, M. 2005. Effective ways to control Botrytis. Greenhouse Mgt. Production 25(12):61-63.

Hausbeck, M.K. and G.W. Moorman. 1996. Managing Botrytisin greenhouse-grown flower crops. Plant Dis. 80(11):1212-1219.

Jarvis, W.R. 1992. Managing diseases in greenhouse crops. APS Press, St. Paul, Minn.

MacDowell, F.D.H. 1972. Phototactic action spectrum for whitefly and the question of color vision. Can. Entomol. 104:299-307.

Malais, M.H. and W.J. Ravensberg. 1992. Knowing and recognizing-The biology of glasshouse pests and their natural enemies. Koppert B.V. and Reed Business Info., Doetinchem, The Netherlands.

Mound, L.A. 1962. Studies on the olfaction and colour sensitivity of Bemisia tabaci (Genn.) (Homoptera: Aleyrodidae). Entomol. Expt. Appl. 5:99-104.

National Academy of Sciences. 1969. Principles of plant and animal pest control, Vol. 3, Insect-pest management and control. Natl. Acad. Sci. Publ. 1695.

Terry, L.I. 1997. Host selection, communication, and reproductive behavior, p. 65-118. In: T. Lewis (ed.). Thrips as crop pests. CAB, Wallingford, U.K.

Tsai, J.H. and K. Wang. 1996. Development and reproduction of Bemisia argentifolii (Homoptera: Aleyrodidae) on five host plants. Environ. Entomol. 25(4):810-816. 